\title{
Desenvolvimento e avaliação de um descaroçador e prensa enfardadeira itinerantes para o beneficiamento do algodão ${ }^{1}$
}

\author{
Jeane F. Jerônimo ${ }^{2}$, Odilon R. R. F. da Silva ${ }^{3}$, Francisco de A. C. Almeida ${ }^{2}$, \\ Valdinei Sofiattíi ${ }^{3}$, Pablo R. C. de França ${ }^{4}$ \& Ziany N. Brandão ${ }^{3}$
}

\begin{abstract}
RESUMO
Novas tecnologias vêm sendo incorporadas ao sistema produtivo da cotonicultura brasileira, visando verticalizar a produção por meio do beneficiamento do algodão em caroço possibilitando, aos produtores ou associações, a agregação de valor à sua produção. Objetivou-se então, com o presente trabalho, desenvolver e avaliar um equipamento de beneficiamento composto de descaroçador e prensa enfardadeira itinerantes. O descaroçador se compõe de: limpador, cilindro de serras, cilindro de escovas, condensador e rolo. A prensa enfardadeira é constituída de chapas de prensagem, cilindros hidráulicos, bomba hidráulica, válvula de controle de acionamento, dispositivos de filtragem do óleo hidráulico e manômetro. Esses equipamentos são montados sobre um reboque composto por chassi de cantoneiras em $U$, quatro rodas de aro 13, pontas de eixo, dois feixes de cinco molas, lastro em chapa de ferro e sistema de frenagem. Na avaliação e validação do conjunto pelos cotonicultores, este conjunto recebeu o conceito "muito bom" quanto ao rendimento do descaroçador, o peso do fardo e em relação à qualidade da fibra obtida. A qualidade da fibra obtida com o conjunto descaroçador e prensa enfardadeira atendeu aos padrões da indústria têxtil.
\end{abstract}

Palavras-chave: máquina beneficiadora de algodão, reboque, qualidade de fibras

\section{Development of a mobile gin and baler press for cotton}

\begin{abstract}
New technologies have been incorporated into the Brazilian cotton production system, in order to verticalize the production through processing, allowing the producers or associations to add value to their production. Thus, the present study aimed to develop and evaluate processing equipment composed of mobile gin and baler press. The ginner consists of cleaner, saw cylinder, cylinder brushes, condenser and coil. The baler press is constituted of pressing sheets, hydraulic cylinders, hydraulic pump, control valve actuation, devices for filtering hydraulic oil and manometer. These devices are mounted on a trailer chassis composed of U-shaped angle iron chassis, four wheels (rim 13), shaft ends, two beams of five springs, steel sheet backing and braking system. In the evaluation and validation of the whole system by the cotton growers, this machine received the concept "very good" concerning efficiency of ginning, the bale weight, and the obtained fiber quality. The quality of fiber obtained with set ginner and baler press meet the standards of the textile industry.
\end{abstract}

Key words: cotton processing machine, trailer, fiber quality

\footnotetext{
1 Parte da tese de Doutorado da primeira autora, apresentada ao Departamento de Engenharia Agrícola da Universidade Federal de Campina Grande ${ }^{2}$ UAEA/UFCG, Av. Aprígio Veloso 882, Bodocongó, CEP 58429-140, Campina Grande, PB. E-mail: janermi@gmail.com; almeida.@deag.ufcg.edu.br 3 Embrapa/CNPA, Rua Oswaldo Cruz, Centenário, CEP 58428-095, Campina Grande, PB. E-mail: odilon.silva@embrapa.br; valdinei.sofiatti@embrapa.br; ziany.brandao@embrapa.br

${ }^{4}$ UFPB/CCA. CEP 58397-000, Areia, PB. E-mail: pabloradames@hotmail.com
} 


\section{INTRODUÇÃO}

As primeiras tentativas para separar a fibra do algodão da semente foram realizadas manualmente por descaroçadores denominados "churka", precursor dos descaroçadores de rolo (Koç \& Demiryürek, 2005). A partir deste modelo o americano Jones McCarthy desenvolveu, em 1740, o descaroçador de rolo, que revolucionou a prática do beneficiamento do algodão e cujo modelo e princípio de funcionamento deram origem aos modernos descaroçadores da atualidade (Holt, 2007).

Em 1792 Eli Whitney desenvolveu o descaroçador de serras, composto de um cilindro de madeira com ganchos de ferro e outro cilindro de escovas, para extrair a fibra. Em 1976 outro americano, Henry Ogden Holmes, inventou o descaroçador de serras, porém com costelas (Holt \& Laird, 2008; 2010).

Essas invenções foram o começo para o aperfeiçoamento das técnicas de beneficiamento do algodão (Holt, 2007). Tais técnicas evoluíram a ponto de provocar um incremento extraordinário das áreas de cultivo por possibilitar, à indústria têxtil, trabalhar com grandes volumes de fibra além de motivar a intensificação dos trabalhos de seleção e de multiplicação de novas cultivares com características tecnológicas de fibra adequadas à crescente modernização da indústria (Silva \& Carvalho, 2008).

A etapa do beneficiamento tem início na colheita e termina com a confecção do fardo, sendo o descaroçamento a etapa principal do beneficiamento que visa à industrialização têxtil e consiste na separação da fibra das sementes (Almeida et al., 2011) por meio de processos mecânicos e pneumáticos, buscando-se manter as características intrínsecas da fibra (Patil \& Patil, 2010). Entretanto, a falta de cuidados nesta etapa pode comprometer o produto com impurezas diversas e indesejáveis, de forma que a remoção desses contaminantes dificulta significativamente o beneficiamento, influindo no preço final do fardo (Le, 2006; Silva et al., 2010).

$\mathrm{Na}$ busca por aumento na produtividade e redução nos custos de produção do algodoeiro no Brasil, novas tecnologias vêm sendo incorporadas ao sistema de produção, com vista a oferecer alternativas de verticalização da produção por meio do seu beneficiamento, com equipamentos compactos e itinerantes o que possibilita, aos produtores ou associações, a agregação de valor à sua produção (Silva et al., 2002).

$\mathrm{O}$ aumento da demanda por equipamentos de beneficiamento simples se deu com o incremento da produção de algodões de tipos especiais, como o orgânico e o de fibra colorida, cuja produção é obtida por agricultores de base familiar. Além do baixo custo o equipamento também deve ser de fácil operação e de fácil transporte para facilitar o deslocamento entre as propriedades vinculadas às associações ou cooperativas, uma vez que o beneficiamento deste tipo de algodão em algodoeiras convencionais não é recomendado em razão da dificuldade de limpeza dos dispositivos da usina, especialmente porque essas algodoeiras recebem algodão de diversas origens e tipos (Carvalho \& Santos, 2003).

Em sua maioria, descaroçadores de "grande porte" com 80 até 198 serras utilizam serras com diâmetro que podem ser de 11 3/4", 12", 16" e 18 " e trabalham a rotações entre 500 e $750 \mathrm{rpm}$ (Holt \& Laird, 2008). Essas máquinas necessitam de uma série de equipamentos para o funcionamento, elevando potencialmente seus custos exigindo, desta forma, grandes volumes de algodão. Em consequência, o uso desta tecnologia fica restrito aos grandes produtores, impossibilitando o acesso de pequenos produtores, sobretudo daqueles que produzem tipos especiais, como o orgânico e o de fibra colorida (Silva et al., 2002).

Em busca de alternativas para o pequeno e médio cotonicultor, a Embrapa Algodão e parcerias desenvolveram um descaroçador de 50 serras. Devido ao seu pequeno porte, este equipamento se torna muito mais econômico podendo ser adquirido por associações de pequenos produtores (Silva et al., 2000); no entanto, referido descaroçador é estacionário, usa energia trifásica e requer um galpão de grande área para sua acomodação (300 a $\left.450 \mathrm{~m}^{2}\right)$. Além disto, a exigência de uma extensa área de plantio envolvendo de 175 a 350 ha de algodão (Silva, 2007) em que a produção desses cotonicultores deve ser transportada até o local da miniusina para o beneficiamento, requer uma adequada logística de transporte, com caminhões e mão-de-obra para organização e gestão da produção o que, às vezes, se torna difícil para determinadas associações ou cooperativas (Silva et al., 2009).

Desta forma, faz-se necessário desenvolver um equipamento compacto e transportável, de beneficiamento simplificado (descaroçamento e formação do fardo), de baixo custo e fácil operação, o qual atue de forma itinerante nas propriedades vinculadas a associações ou cooperativas.

Objetivou-se, então, com o presente trabalho, desenvolver e avaliar um equipamento de beneficiamento composto de descaroçador e prensa enfardadeira itinerantes.

\section{Material e Métodos}

A máquina descaroçadora, a prensa enfardadeira e o reboque, foram projetados seguindo-se princípios fundamentados em modelos anteriores descritos por Silva et al. (2009) em parceria da Embrapa Algodão com a Unidade Acadêmica de Engenharia Agrícola (UAEA) da Universidade Federal de Campina Grande. O conjunto foi desenvolvido na Metalúrgica Barros Ltda., indústria situada em Campina Grande, PB. Após o desenvolvimento e montagem dos equipamentos no reboque, os mesmos foram validados junto aos cotonicultores, no município de Prata, PB.

A descrição de cada componente do conjunto: descaroçador, prensa enfardadeira e reboque, é feita a seguir.

\section{Alimentador manual com limpador}

$\mathrm{Na}$ parte superior do descaroçador foram instalados o alimentador manual, construído em chapas de aço de $0,325 \mathrm{~cm}$ de espessura no formato retangular e o limpador, composto de três cilindros de $11,5 \times 41,5 \mathrm{~cm}$ envolvidos com pinos de $1 / 4 \mathrm{x}$ 1"; três grelhas para a retirada das impurezas que acompanham o algodão em caroço e polias e correias de acionamento (Figura 1). O conjunto (alimentador manual com limpador) foi fixado ao descaroçador por meio de parafusos de $0,8 \mathrm{~cm}$.

\section{Descaroçador}

O equipamento de descaroçamento foi montado sobre uma estrutura de aço de $0,825 \mathrm{~cm}$ de espessura (chassi de 


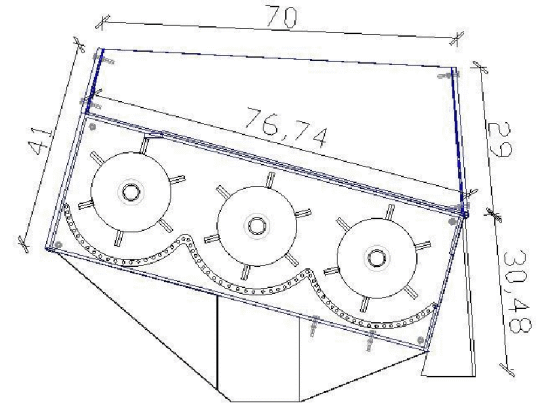

Figura 1. Vista lateral do alimentador manual com limpador em escala reduzida $(\mathrm{cm})$

sustentação) a qual prende outra estrutura denominada "suporte de sustentação das costelas" conforme Koç \& Demiryürek (2005) cujas partes formam a base do descaroçador (câmara de descaroçamento) (Figura 2A), onde foi montado um eixo com 25 serras de 12" de diâmetro cada um, espessura $0,11 \mathrm{~cm}$, ângulo de $28^{\circ}$ e 264 dentes cada serra. As serras são afastadas uma das outras, por 24 separadores de alumínio de 15,5 x 1,54 $\mathrm{cm}$, permitindo o encaixe das 26 costelas (marca Lumus); um cilindro de $23,2 \times 41,5 \mathrm{~cm}$ contendo 17 escovas de crina de cavalos com a finalidade de retirar a fibra das serras e outro cilindro de $41,5 \times 30,0 \mathrm{~cm}$ coberto com tela galvanizada de malha $14 \mathrm{~mm}$, denominada condensador, para aglutinar a fibra

A.
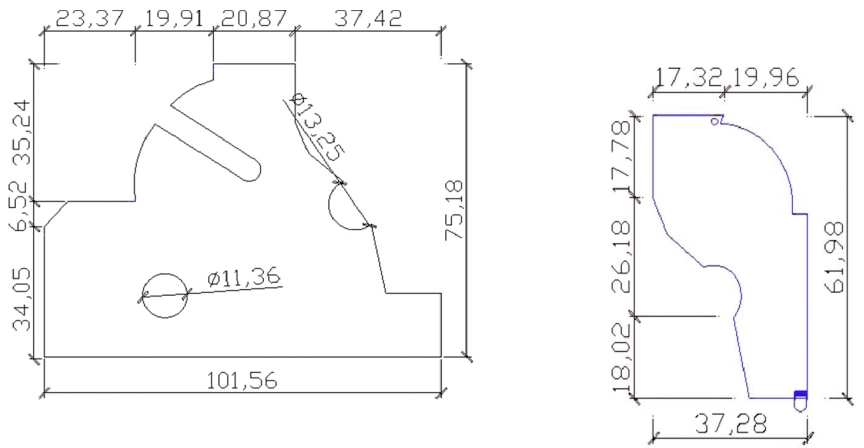

B.

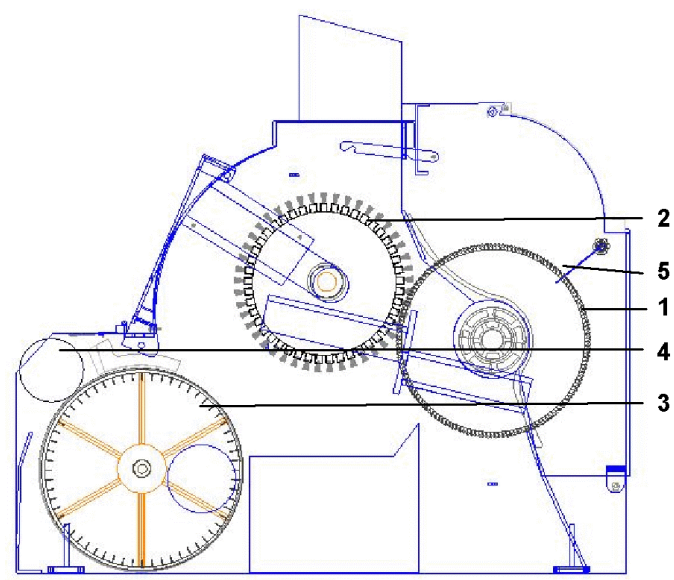

Figura 2. Vista lateral do chassi de sustentação e suporte de sustentação das costelas do descaroçador (A) descaroçador completo. (B) 1. Cilindro de serras; 2. Cilindro de escovas; 3. Condensador; 4. Rolo de condução da manta de algodão; 5 . Pente em escala reduzida $(\mathrm{cm})$ em forma de manta, além de um motor de $3 \mathrm{cv}$ e 4 polos de sistema trifásico para acionamento do conjunto (Figura 2B).

\section{Prensa enfardadeira}

A vista frontal da prensa enfardadeira é apresentada na Figura 3. Este equipamento possui as seguintes dimensões: altura de $200 \mathrm{~cm}$, frente de $120 \mathrm{~cm}$, profundidade de $70 \mathrm{~cm}$ e peso de $800 \mathrm{~kg}$. Foi desenvolvido com base nos estudos de Silva et al. (2009) sendo sua construção em chapas de aço SAE 1020. Possui uma bomba hidráulica de engrenagens, dois cilindros hidráulicos medindo $3,7 \mathrm{~cm}$ de diâmetro com $100 \mathrm{~cm}$ de curso dos pistões, comando de válvulas de controle dos cilindros hidráulicos, uma chapa móvel para prensagem do algodão, uma caixa de prensagem com medidas no padrão internacional $100 \times 80 \times 60 \mathrm{~cm}$ e um motor de $5 \mathrm{cv}$ com 4 polos de sistema trifásico para acionamento do sistema hidráulico.

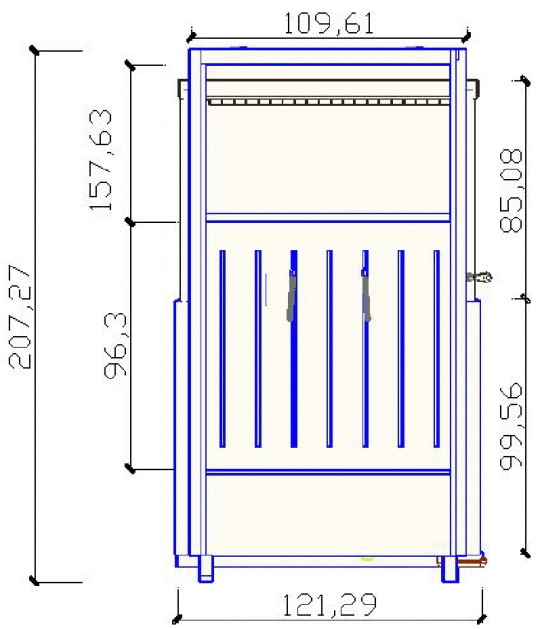

Figura 3. Vista frontal da prensa enfardadeira em escala reduzida $(\mathrm{cm})$

O circuito hidráulico (Figura 4) que possibilita a prensagem do algodão para a formação do fardo, ocorre por meio de vários componentes, dentre eles o principal é a bomba hidráulica, responsável pelo bombeamento e circulação do óleo por todo o circuito. A bomba hidráulica succiona o óleo do tanque e o encaminha para o distribuidor, cuja função é distribuir o óleo para os dois cilindros hidráulicos. Os cilindros hidráulicos são os mecanismos responsáveis pelo movimento vertical da chapa de prensagem. A prensa é acionada pelo motor da bomba hidráulica, que faz a sucção do óleo armazenado no tanque e o bombeia até o distribuidor, sendo possível verificar a pressão do óleo por meio de um manômetro. O movimento dos cilindros hidráulicos se dá pelo bombeamento do óleo concomitantemente com a abertura ou fechamento das válvulas de controle de passagem do óleo pelo distribuidor. De acordo com o movimento desejável, o distribuidor vai injetar ou retirar óleo do compartimento do êmbolo dos cilindros hidráulicos; isto é, quando a chapa de prensagem é acionada injeta-se óleo no êmbolo do cilindro pela mangueira acoplada na parte superior e se retira óleo pela mangueira acoplada na parte inferior do cilindro hidráulico, simultaneamente promovendo, assim, o movimento da chapa de prensagem. Para a chapa de prensagem aliviar a pressão sobre o algodão, ocorre um processo contrário. 


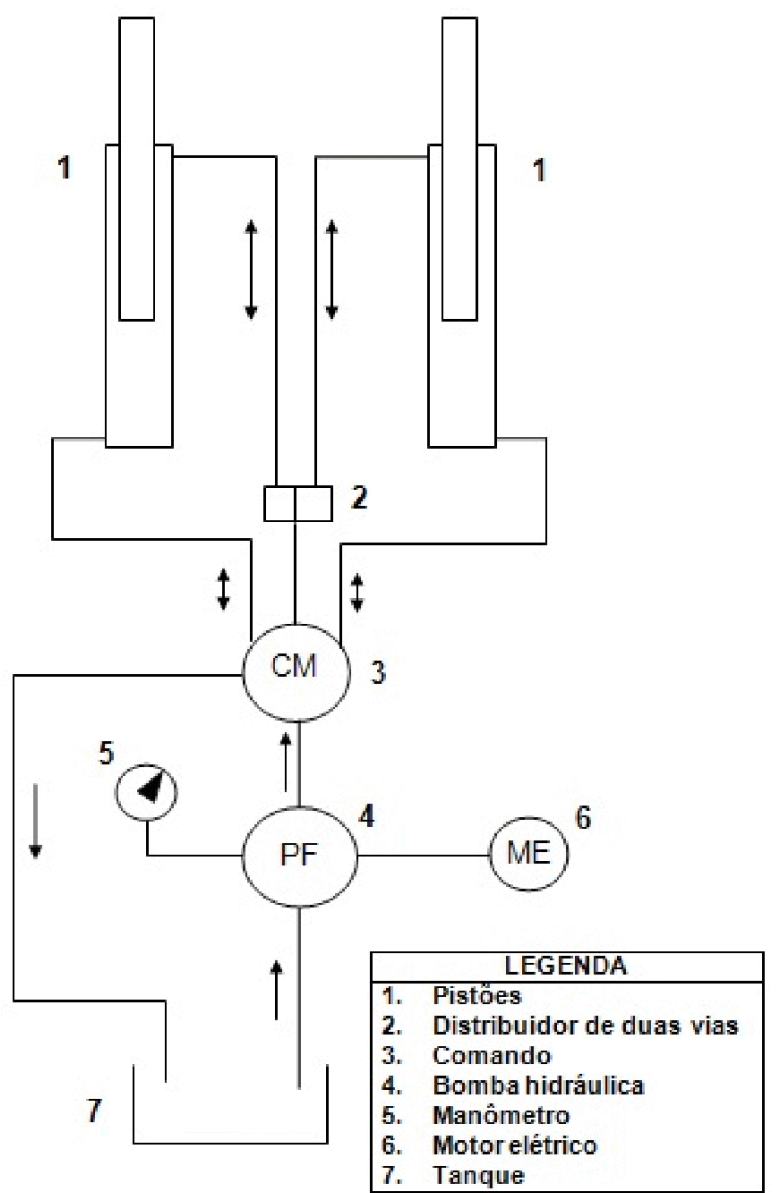

Figura 4. Representação esquemática do circuito hidráulico

\section{Reboque}

A vista inferior do reboque é apresentada na Figura 5, que foi construído com cantoneiras em formato $\mathrm{U}$ de 4 polegadas, 4 rodas de aro 13 e eixo com comprimento de $100 \mathrm{~cm}$ entre pontas de eixo, contendo dois feixes de cinco molas de um quarto por 6 $\mathrm{cm}$ e lastro em chapa de ferro de um oitavo de polegada dotado sistema de frenagem própria para não permitir seu deslocamento quando retirado do veículo transportador, proporcionando segurança aos que operam o conjunto descaroçador e a prensa enfardadeira.

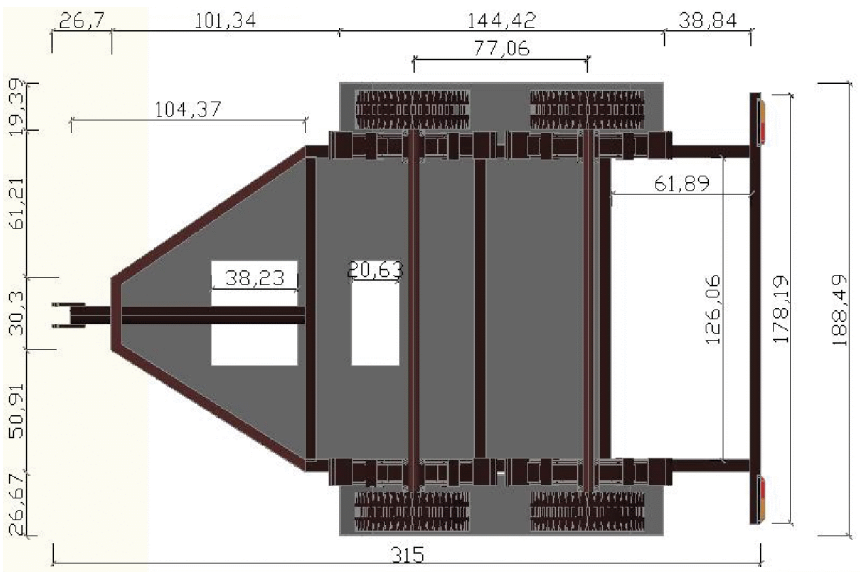

Figura 5. Vista inferior do reboque em escala reduzida $(\mathrm{cm})$
Funcionamento do conjunto descaroçador, prensa enfardadeira e reboque

O funcionamento do conjunto foi baseado nos seguintes mecanismos: processo de limpeza retirada das impurezas; alimentação do descaroçador; descaroçamento para a separação da semente da fibra; prensa enfardadeira para formação do fardo e reboque para transportar o conjunto (Figura 6).

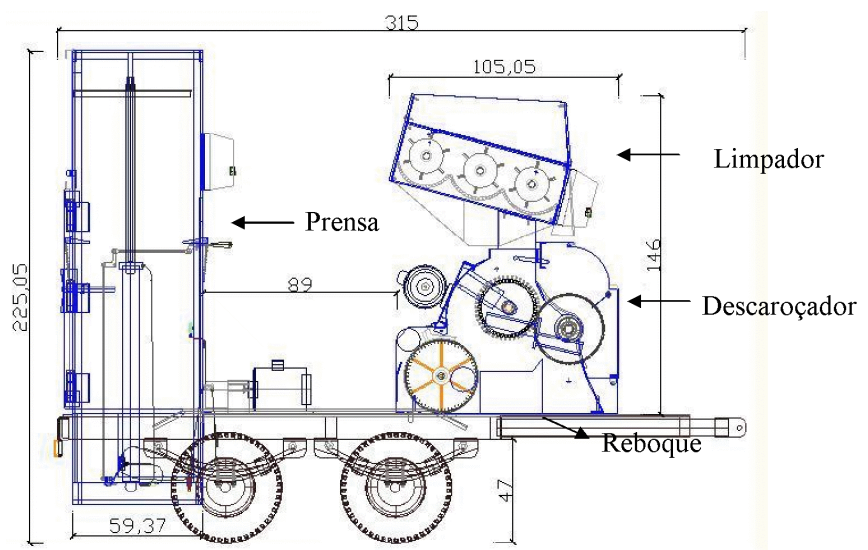

Figura 6. Representação esquemática do conjunto do equipamento desenvolvido em escala reduzida $(\mathrm{cm})$ Validação e avaliação do conjunto descaroçador e prensa
enfardadeira junto aos cotonicultores

Em referência à avaliação do desempenho maquinado do equipamento, foram utilizados julgamentos subjetivos e objetivos. A avaliação subjetiva consistiu na aplicação de questionário junto aos cotonicultores que fizeram uso do conjunto descaroçador, prensa enfardadeira e reboque no beneficiamento do algodão, no Município de Prata, PB.

A cultivar beneficiada foi a BRS Aroeira procedente de campos experimentais de cooperados da Embrapa Algodão; após o beneficiamento e enfardamento do algodão de cada produtor, aplicou-se o questionário contendo 15 itens, na escala de 1 a 4, variando de acordo com os parâmetros apresentados na Tabela 1; usou-se algodão proveniente de 13 produtores distintos, cada um utilizando, individualmente, o equipamento, para o beneficiamento do algodão de produção própria.

Tabela 1. Escalas com níveis de 1 a 4 utilizadas para avaliar os 15 itens

\begin{tabular}{|c|c|c|c|c|}
\hline \multirow{2}{*}{ Itens } & \multicolumn{4}{|c|}{ Escala } \\
\hline & 1 & 2 & 3 & 4 \\
\hline 1,2 & Leve & Médio & Forte & Exaustivo \\
\hline $3,4,5$ & Fraco & Leve & Médio & Forte \\
\hline $6,7,8,14$ & Fraco & Regular & Bom & Ótimo \\
\hline 9,10 & $\begin{array}{l}\text { Manejo } \\
\text { simples }\end{array}$ & $\begin{array}{l}\text { Baixa } \\
\text { complexidade }\end{array}$ & $\begin{array}{l}\text { Média } \\
\text { complexidade }\end{array}$ & $\begin{array}{l}\text { Alta } \\
\text { complexidade }\end{array}$ \\
\hline 11,12 & Adequado & Inadequado & Ajuste & Recomenda \\
\hline 13,15 & Nenhuma & Pouca & Média & Muita \\
\hline
\end{tabular}

Foi realizada uma análise descritiva dos dados e feita a descrição das frequências de respostas obtidas nas variáveis do questionário (Barbetta, 2010) com a apresentação dos resultados obtidos apresentadas em um conjunto de tabelas representativas.

Os dados referentes ao questionário foram organizados em uma planilha eletrônica e os resultados obtidos com a utilização do software estatística SPSS versão 15.0. 


\section{Resultados E Discussão}

À caixa acumuladora ou reservatório, coube receber o algodão em caroço para o beneficiamento e a ela foi anexado um limpador (Figura 7A) dotado de três cilindros batedores de rolo com pinos e grelhas, desenvolvidos para remover as impurezas. No descaroçador as serras foram distribuídas em um eixo central espaçadas com distanciamento uniforme por meio de separadores (Figura 7B) e um conjunto de costelas ordenadas equidistantes (Figura 7C) em um dispositivo denominado suporte de sustentação, que fica preso ao chassi de sustentação formando a câmara de descaroçamento (Koç \& Demiryürek, 2005). Na parte inferior desta câmara foi preso um dispositivo de regulagem (pente) para controle da permanência das sementes junto às serras até a extração das fibras (Figura 7D).

Na Figura 7E é apresentada a parte posterior do cilindro de serras à qual foi anexado um cilindro de escovas que trabalha junto ao cilindro de serras porém com maior rotação para retirada da fibra contida nos dentes das serras (Foulk et al., 2007).

Para a saída da fibra em formato de manta foi colocado, na parte traseira, um condensador formado por um cilindro de tela de arame galvanizado de baixa rotação e um cilindro de rolo, com o objetivo de se realizar a retenção, aglutinação e remoção da fibra, respectivamente (Figura 7F).

A. B.

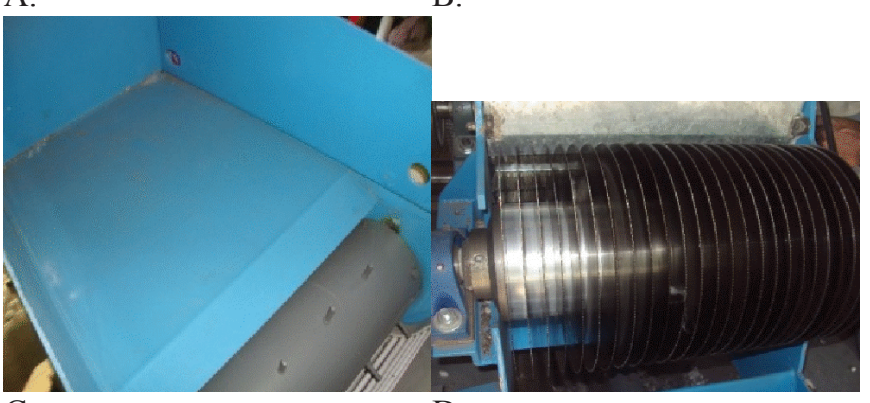

C.

D.

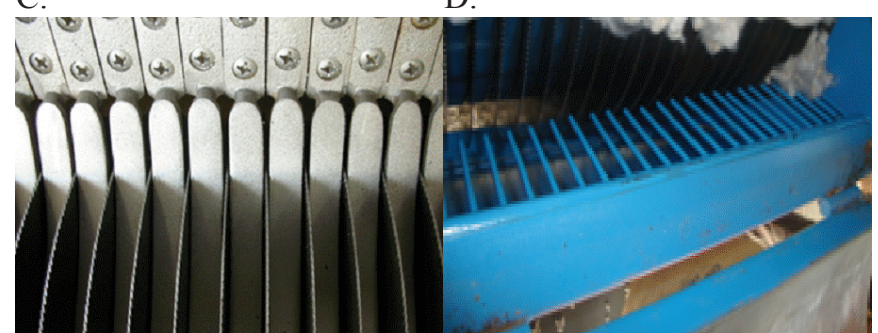

E.

F.

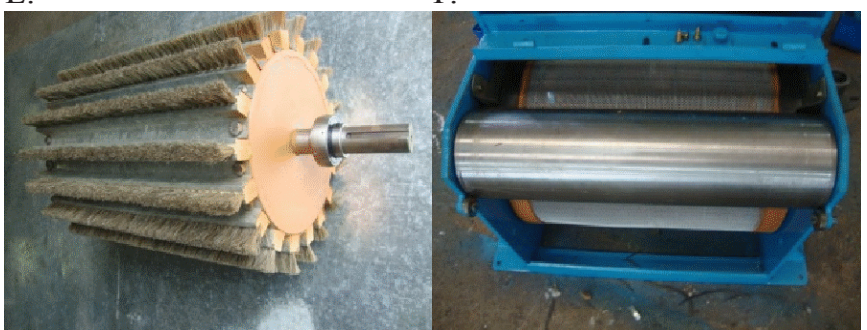

Figura 7. Fotos dos principais componentes do descaroçador de 25 serras

\section{Funcionamento do descaroçador de 25 serras}

$\mathrm{O}$ processo de beneficiamento no descaroçador iniciou-se ao se colocar o algodão em caroço no reservatório denominado alimentador manual; em seguida, o algodão passou no limpador formado por pinos e grelhas, no qual feita a separação das impurezas (Figura 8A e B); depois desta operação o algodão seguiu para o descaroçamento realizado pelas serras e costelas (Figura 8C); os dentes das serras liberaram as sementes entre elas, formando um cilindro de algodão na câmara de descaroçamento devido as serras trabalharem em rotação contrária a este (Armijo \& Gillum, 2007). Feita a separação da fibra das sementes, estas passaram pelo dispositivo de regulagem e foram conduzidas para fora do descaroçador (Figura 8D). As fibras arrastadas pelo cilindro de escovas para o condensador (Figura 8E) foram aglutinadas formando uma manta (Figura 8F).

A.

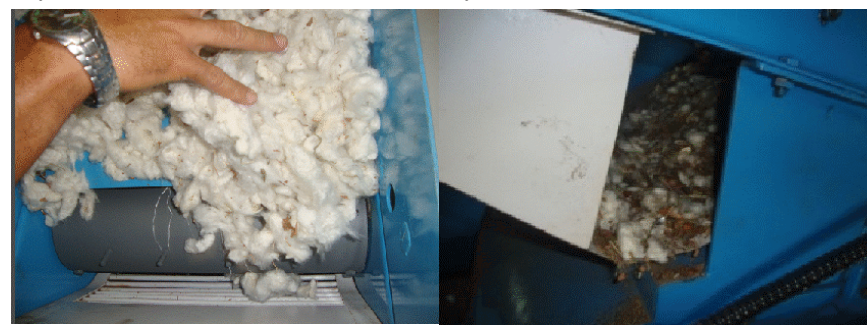

C.

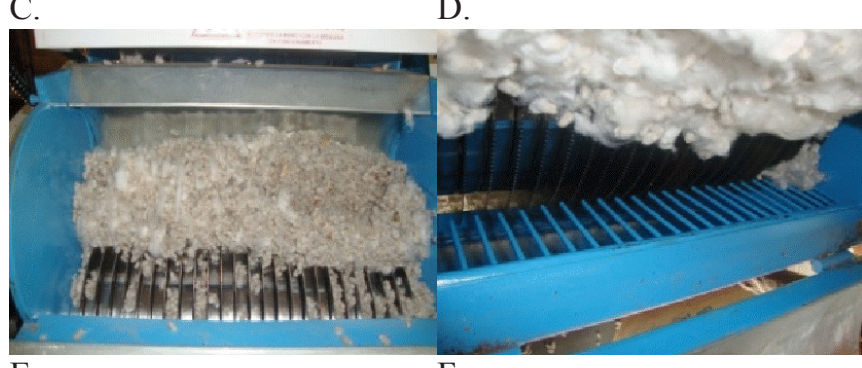

E.

F.

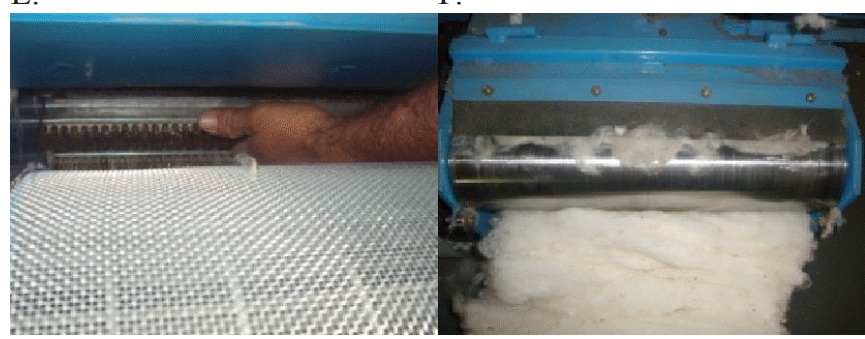

Figura 8. Fotos da sequência de funcionamento do descaroçador de 25 serras: (A) alimentador e limpador, (B) separação das impurezas, (C) cilindro de serras e costelas, (D) dispositivo de regulagem, (E) cilindro de escovas e condensador e (E) rolo em forma de manta

\section{Desenvolvimento da prensa enfardadeira}

A prensa enfardadeira (Figura 9) foi construída em chapas e cantoneiras de aço, dotada de um sistema hidráulico, acionado por uma bomba de engrenagens para fluido hidráulico o qual, por sua vez, foi injetado em dois cilindros hidráulicos com pistões colocados nas laterais da caixa de prensagem, constituídos de um êmbolo e camisa que, de forma conjunta, acionaram uma chapa móvel (superior) da caixa de prensagem, juntamente com outra chapa fixa na parte inferior para a produção do fardo, além de uma porta com abertura na parte traseira com fechos mecânicos para a retirada do fardo.

A alimentação da prensa enfardadeira foi feita manualmente utilizando-se a fibra produzida na operação de descaroçamento, 

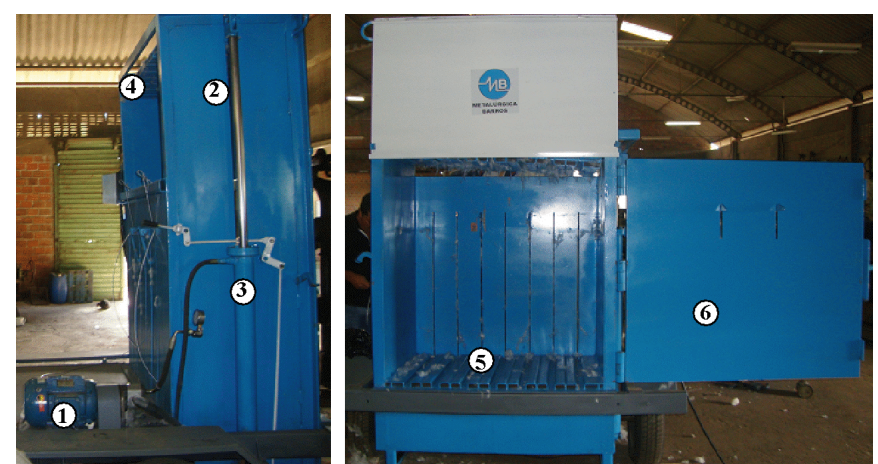

Figura 9. Fotos da prensa enfardadeira com os principais componentes. 1 - motor elétrico com bomba hidráulica; 2 - êmbolo ou pistão do cilindro hidráulico; 3 - camisa do cilindro hidráulico; 4 - chapa de prensagem móvel; 5 - chapa de prensagem fixa; 6 - porta para retirada do fardo

a qual era depositada na caixa de armazenamento até o enchimento completo; depois, a fibra foi compactada acionando-se o dispositivo de prensagem (Figura 10A) operação esta repetida de seis a oito vezes até formar o fardo com peso em torno de $80 \mathrm{~kg}$; este peso variou de acordo com a quantidade de algodão utilizado; em seguida abriu-se a porta da enfardadeira para se proceder à amarração do fardo com seis fios de arame (Figura 10B) separados especialmente para tal fim. A retirada do fardo foi feita por meio de duas correntes acionadas pelo sistema hidráulico da prensa; logo após esta operação o fardo foi pesado e identificado (Figura 10C).

\section{Desenvolvimento do reboque}

Uma representação do reboque pode ser vista na Figura 11. A prensa e o descaroçador foram acoplados ao reboque constituído de um chassi confeccionado em cantoneiras em formato de "U"; nele foram colocados dois eixos dotados de quatro rodas pneumáticas para suportar e transportar o conjunto beneficiador; aos eixos foram anexadas as molas planas para o amortecimento do peso em razão das oscilações do terreno; também foram inseridos, ao chassi, uma chapa de ferro e o dispositivo para o atrelamento do reboque à fonte de tração.

O eixo do reboque foi dimensionado com um elevado valor de segurança suportando 3,48 e 3,07 vezes os valores de flexão

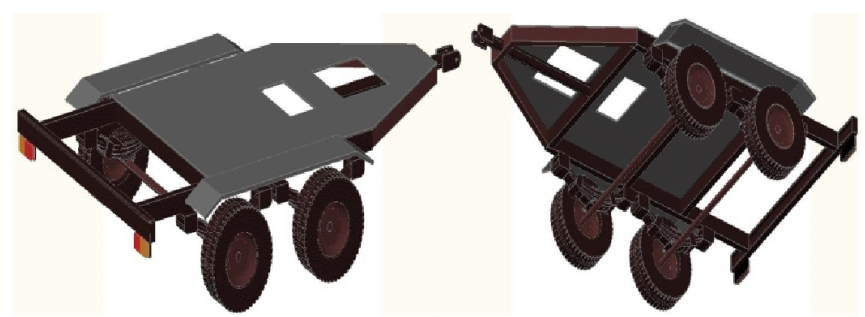

Figura 11. Representação gráfica do reboque, com vista superior e inferior

e fadiga, respectivamente apresentando, desta forma, resistência para trabalhar em qualquer situação.

Para o dimensionamento por flexão do chassi o coeficiente de segurança calculado foi de 24,7, ou seja, o material suporta uma tensão 24,7 vezes maior do que a que está sendo aplicada garantindo, desta maneira, que a estrutura do chassi não falhe devido à flexão.

\section{Conjunto descaroçador e prensa enfardadeira itinerantes}

A Figura 12 representa o conjunto descaroçador, prensa enfardadeira e reboque no seu estágio final de desenvolvimento. Como se observa, o descaroçador e a prensa enfardadeira podem ser facilmente deslocados para as propriedades dos cotonicultores sobre o reboque desenvolvido para esta finalidade.

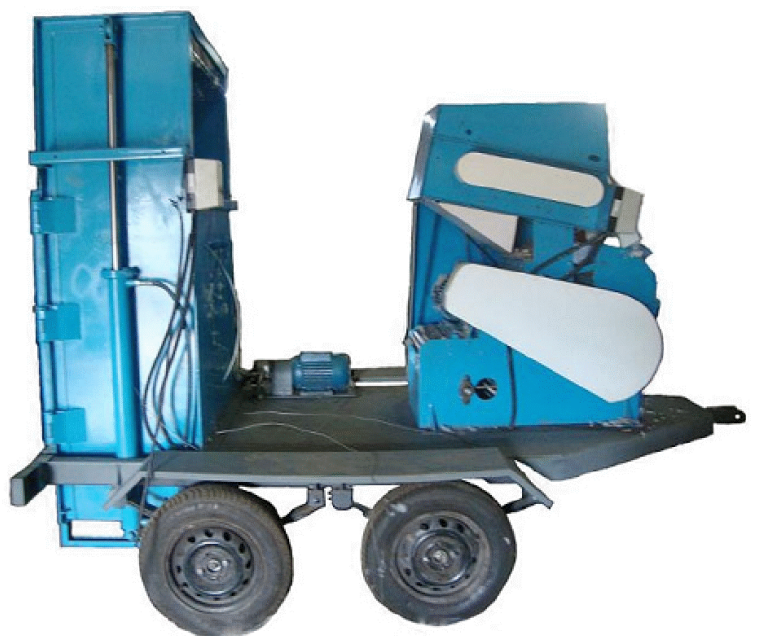

Figura 12. Foto da configuração final do conjunto descaroçador e prensa enfardadeira itinerantes

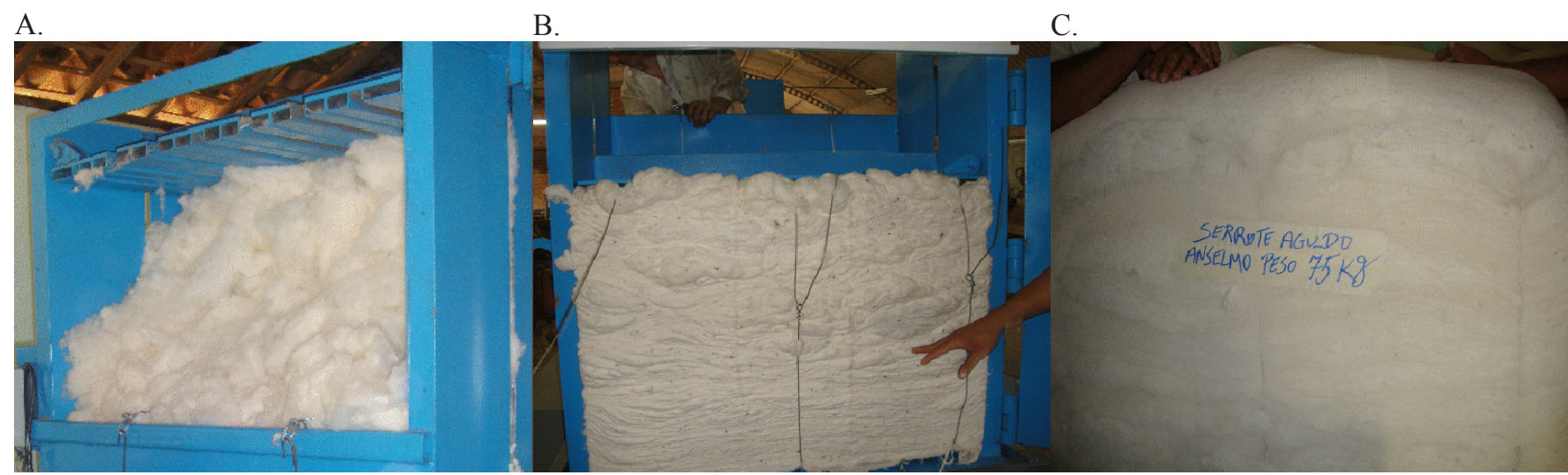

Figura 10. Fotos sequenciando a formação do fardo de algodão pela prensa enfardadeira: (A) alimentação e prensagem, (B) amarração do fardo e (C) pesagem e identificação do fardo 
Tabela 2. Percepção do usuário sobre os itens avaliados

\begin{tabular}{|c|c|c|c|c|c|c|c|}
\hline \multirow{2}{*}{\multicolumn{2}{|c|}{ Itens avaliados }} & \multicolumn{4}{|c|}{ Escala de 1 a 4 - \% } & \multirow{2}{*}{ Média } & \multirow{2}{*}{ DP } \\
\hline & & 1 & 2 & 3 & 4 & & \\
\hline 2. & Postura física dos operadores & 69,2 & 15,4 & 7,7 & 7,7 & 1,54 & 0,97 \\
\hline 4. & Risco de acidente & 15,4 & 15,4 & 7,7 & 61,5 & 3,15 & 1,21 \\
\hline 5. & Fonte de ruído & 38,5 & 38,5 & 15,4 & 7,6 & 1,92 & 0,95 \\
\hline 6. & Desempenho do descaroçamento $\left(\mathrm{kg} \mathrm{h}^{-1}\right)$ & 0,0 & 23,1 & 46,1 & 30,8 & 2,85 & 0,90 \\
\hline 7. & Quantidade e qualidade da pluma & 0,0 & 0,0 & 46,2 & 53,8 & 3,08 & 1,04 \\
\hline 10 & Manutenção e reparos elementares & 69,2 & 7,7 & 15,4 & 7,7 & 1,62 & 1,04 \\
\hline 11 & Avaliação geral do conjunto & 61,5 & 0,0 & 30,8 & 7,7 & 1,85 & 1,14 \\
\hline 12 & Desempenho do transporte do reboque & 92,3 & 0,0 & 0,0 & 7,7 & 1,23 & 0,83 \\
\hline 13 & Melhora sua renda com a cultura do algodão & 0,0 & 0,0 & 23,1 & 76,9 & 3,77 & 0,44 \\
\hline & Contribui para a organização e produção coletiva dos AF & 0,0 & 0,0 & 53,8 & 46,2 & 3,46 & 0,52 \\
\hline & Tecnologia importante para algodoeiros & 0,0 & 0,0 & 23,1 & 76,9 & 3,77 & 0,44 \\
\hline
\end{tabular}

O conjunto descaroçador mostrou-se eficaz e de grande utilidade para a obtenção da fibra do algodão visto que possibilita a limpeza, o descaroçamento e a produção de fardos em um único equipamento, desenvolvidos especificamente para serem transportados com segurança em reboque próprio, sem que haja necessidade de desmonte.

Quando comparado a outros equipamentos similares, o conjunto descaroçador de 25 serras apresentou a vantagem de ser itinerante e levar ao produtor dois equipamentos em um único conjunto.

Com relação ao descaroçador, o melhor desempenho foi o trabalhado com serras de 12" e dispositivo de limpeza (limpador) quando foram comparadas as características tecnológicas da fibra e físicas e fisiológicas das sementes do algodão.

A prensa operava de acordo com o fluxo da produção do descaroçador de 25 serras, no qual a pluma era conduzida de forma manual para a caixa de armazenamento da prensa. A prensagem foi repetida de 6 a 8 vezes, até a obtenção de um fardo com peso de $80 \mathrm{~kg}$, com a vantagem de ser transportável.

\section{Validação do equipamento pelos cotonicultores}

Na validação do conjunto descaroçador e prensa obtiveramse os valores percentuais dos 15 itens avaliados conforme apresentado na Tabela 2. Verificou-se que o valor médio do item 12 que indica a satisfação dos produtores no desempenho do reboque, foi de 92,3\%; para o nível de segurança (item 3) a resposta de $61,5 \%$ indica que o equipamento se encontra dentro dos padrões estabelecidos ao seu funcionamento (escala 3) e, também, que este item representa a maior média relacionada ao risco.

Mediante os valores contidos nas Tabelas 1 e 2 para "esforço físico" e considerando sua posição, verifica-se que este foi considerado leve e médio, respectivamente, por $46,2 \%$ dos cotonicultores, resultado indicador de que o conjunto da máquina não exigiu muito esforço físico por parte do operador.

Para "postura física dos operadores", a porcentagem de aceitação do conjunto ficou na escala leve $(69,2 \%)$, percentual indicador de que o equipamento descaroçador e prensa não prejudicou a postura do operador.

O nível "segurança do operador" ficou entre leve $(15,4 \%)$, médio $(61,5 \%)$ e forte $(23,1 \%)$ cujo resultado indica que o operador deve ter cuidados, especialmente quando estiver trabalhando no descaroçamento e prensa enfardadeira e sinaliza, também, a necessidade de melhorias no item 3 e na escala 4, quando de novos lançamentos do conjunto. Para o item "risco de acidentes" o maior valor foi revelado na escala forte $(61,5 \%)$ requerendo, portanto, o mesmo tratamento do nível de segurança do operador. Apesar disto, o valor médio $(7,7 \%)$ obtido para "risco de acidente" se encontra dentro dos padrões de aceitação dos operadores da máquina e, ainda, que $15,4 \%$ avaliaram o conjunto atribuindo valores fracos e leves, respectivamente com relação a este nível de acidente, avaliação que se traduziu em uma boa segurança.

A média de $179,4 \mathrm{~kg} \mathrm{~h}^{-1}$ de algodão obtido no processo de descaroçamento colocou o "desempenho do descaroçador" como ótimo (30,8\% escala 4$)$ e bom $(46,1 \%$ escala 3$)$, traduzindo-se em satisfação plena dos operadores.

Verificou-se, com base na análise dos resultados da "quantidade e qualidade da pluma", que esta foi avaliada em bom $(46,2 \%)$ e ótimo $(53,8 \%)$ indicando boa resposta no processo de descaroçamento. Com relação ao tempo gasto para a confecção do fardo o qual pesou, no final, em média 71 $\mathrm{kg}$, enquadrando-se na escala $3(53,8 \%)$ que representa "bom fardo", sendo avaliado em ótimo, com 30,8\%.

A "avaliação sobre a operação do conjunto" (item 9) e "manutenção e reparos elementares" (item 10) foram consideradas, pelos cotonicultores, satisfatória como manejo simples (escala 1) respectivamente.

Em uma avaliação geral do conjunto (item 11) constatou-se que o conjunto descaroçador e prensa enfardadeira itinerantes é adequado para atender às cooperativas e às associações de cotonicultores. Para o "desempenho do transporte do reboque" (item 12) a avaliação recebeu conceito adequado, representado por $92,3 \%$ de aceitação, e o conceito "muito bom" com 76,9\% de satisfação para os itens 13 e 15, respectivamente; o mesmo conceito com $46,2 \%$ para o item 14 - contribuindo para a organização e produção coletiva da agricultora familiar.

\section{Conclusões}

1. O conjunto descaroçador de 25 serras e prensa enfardadeira itinerantes desenvolvidos, mostraram-se eficientes no descaroçamento e enfardamento do algodão. 
2. O dimensionamento do reboque representado pelo eixo e chassi apresentou coeficiente de segurança elevado, ou seja, o conjunto de equipamento pode ser transportado com segurança para executar as atividades de beneficiamento.

3. O conjunto descaroçador e prensa enfardadeira atendeu, com a eficiência requerida pela indústria têxtil, ao processamento do algodão, tendo recebido o conceito "muito bom" pelos cotonicultores de base familiar.

\section{Literatura Citada}

Almeida, F. de A. C.; Silva, O. R. R. F. da; Santos, J. F. dos; Gouveia, J.P. G. de. Desenvolvimento e avaliação de descaroçador para o beneficiamento do algodão. Revista Brasileira de Engenharia Agrícola e Ambiental, v.13, p.607-614, 2011.

Armijo, C. B.; Gillum, M. N. High-speed roller ginning of upland cotton. Applied Engineering in Agriculture, v.3, p.137-143, 2007.

Barbetta, P. A. Estatística aplicada ás ciências sociais. 7.ed. Florianópolis: UFSC, 2010. 320p.

Carvalho, L. P.; Santos, J. W dos. Respostas correlacionadas do algodoeiro com seleção para coloração da fibra. Pesquisa Agropecuária Brasileira, v.38, p.79-83, 2003.

Foulk, J. A.; Dodd, R. B.; McAlister, D.; Chun, D.; Akin, D. E.; Morrison, H. Flax-cotton fiber blends: Miniature spinning. Industrial Crops and Products, v.25, p.8-16, 2007.

Holt, G. A. Design of experiments optimization study on the powered roll gin stand: part I. American Society of Agricultural and Biological Engineers, v.50, p.765-772, 2007.

Holt, G. A.; Laird, J. W. Initial fiber quality comparisons of the power roll gin stand to three different makes of conventional gin stands. American Society of Agricultural and Biological Engeineers, v.24, p.295-299. 2008.

Holt, G. A.; Laird, J. W. Power roll gin stand technology: Evaluation and optimization of rib rail angle and ginning point modifications on a retrofitted lummus gin stand. American Society of Agricultural and Biological Engineers, v.26, p.209-215, 2010.
Koç, E.; Demiryürek, O. Theoretical investigation of separator units in saw-gin machines. I: Cotton flow rate estimation. Fibres \& Textiles in Eastern Europe, v.13, p.78-83, 2005.

Le, S. Cleaning performance of modified cylinder cleaners. Journal of Cotton Science, v.10, p.273-283, 2006.

Patil, P. G.; Patil, V. Development of prototype double roller gin with improved power transmission and its performance evaluation. Journal of Engineered Fibers and Fabrics, v.5, p.20-25, 2010.

Silva, O. R. R. F. da. Miniusinas de 20 e 50 serras. In: Congresso Brasileiro de Algodão, 6, Uberlândia. Anais... Uberlândia: UFMG, 2007. CD-Rom

Silva, O. R. R. F. da.; Cartaxo, W. V.; Carvalho, O. S.; Araújo, J. M. de. Mini-usina de beneficiamento de algodão de 50 Serras e prensa hidráulica, uma alternativa para associação de pequenos produtores. Campina Grande: Embrapa Algodão, 2000. 5p.

Silva, O. R. R. F. da; Carvalho, O. S. Beneficiamento. In: Beltrão, N. E. de M.; Azevedo, D. M. P. (ed.) O Agronegócio do algodão no Brasil. v.2. Brasília: Embrapa Informação Tecnológica, 2008. Cap.34, 1309p.

Silva, O. R. R. F. da.; Santana, J. C. F. de; Cartaxo, W. V.; Luz, M. J. S. da; Santos, J. W. dos. Influência do descaroçamento nas características tecnológica da fibra do algodão analisado pelo HVI (high volume instruments) e pelo AFIS (advanced fiber information system). Revista Brasileira de Oleaginosas e Fibrosas, v.6, p.497-501, 2002.

Silva, O. R. R. F. da; Sofiatti, V.; Cartaxo, W. V.; Barbosa, V. de S. C.; Wanderley, M. J. R. Algodão em pluma. Brasília: Embrapa Informação Tecnológica, 2009. 44p.

Silva, O. R. R. F. da; Sofiatti, V.; Santana, J. C. F.; Wanderley, M. J. R.; Santos, J. W dos. Impacto do beneficiamento sobre o número de neps e quantidade de impurezas da fibra do algodão. Revista Brasileira de Engenharia Agrícola e Ambiental, v.14, p.107-112, 2010. 